\title{
UM OLHAR SOBRE O VI CONGRESSO PAULISTA DE SAÚDE PÚBLICA
}

\author{
Paulo Fernando Capucci ${ }^{\star 1}$ \\ Cleide Lavieri Martins ${ }^{\star 2}$ \\ Aurea Maria Zöllner lanni ${ }^{\star 3}$ \\ Nivaldo Carneiro Junior ${ }^{* 4}$ \\ Cláudia Maria Bógus ${ }^{\star 3}$
}

RESUMO: Os autores apresentam uma avaliação do VI Congresso Paulista de Saúde Pública a partir de documentos de preparação do evento e de avaliação dos Congressistas. Comentam aspectos da organização e informa sobre origem e categorias profissionais dos congressistas.

PALAVRAS-CHAVE: saúde pública, evento cientifico, avaliação, saúde na cidade.

\footnotetext{
* Membros da Diretoria da Associação Paulista de Saúde Pública - APSP - Rua Cardeal Arcoverde, 1749 - $7^{\circ}$ andar Conj. 78B - email apsp@apsp.org.br

1. Secretaria Municipal da Saúde - PMSP

2. Faculdade de Saúde Pública da USP

3. Instituto de Saúde - Secretaria de Estado da Saúde de São Paulo

4. Fundação A.V.Carvalho - Centro de Saúde Escola Barra Funda - Santa Casa
} 


\section{INTRODUÇÃO}

A Associação Paulista de Saúde Pública (APSP), fundada em 15 de dezembro de 1972 por profissionais e docentes da saúde pública e coletiva, é uma sociedade civil sem fins lucrativos. Tendo como mandato, entre outros, promover o debate sobre temas que constam da agenda da área, nesses anos de existência a APSP tem realizado diversas atividades, destacando-se os Congressos Paulistas de Saúde Pública. Esses eventos têm se constituído em um espaço de dinamização das diversas discussões que envolveram os diferentes profissionais da área da saúde. Este trabalho é o relato de uma avaliação do VI Congresso Paulista de Saúde Pública, realizado em 1999.

Evento regional de importância e freqüência crescentes, o Congresso Paulista de Saúde Pública vem se firmando como espaço de análise e debate de políticas e tecnologias para a área da saúde pública em nosso estado e pals. Sua edição inaugural se deu em outubro de 1977, em evento conjunto com a Sociedade Brasileira de Higiene que realizava à época o seu XIX Congresso. Os temas oficiais foram: "Programas de Nutrição em Saúde Pública, Recursos Humanos em Saúde, Problemática dos Serviços de Saúde Urbanos e Rurais, e Saneamento Básico nas Ações de Saúde".

O II Congresso Paulista de Saúde Pública foi realizado em abril de 1983, tendo como tema "Política Nacional de Saúde". Neste mesmo evento, realizou-se o I Congresso Nacional da ABRASCO, promovido pela Associação Brasileira de Saúde Coletiva - ABRASCO.

O III Congresso Paulista teve por tema "SUS - Sistema Único de Saúde: conquista da sociedade" e foi realizado em julho de 1989, em conjunto com o ll Congresso Brasileiro de Saúde Coletiva.

O IV Congresso aconteceu em julho de 1993 e seu tema foi "Como fazer da Municipalização o caminho: um desafio para a Saúde Pública".

O V Congresso Paulista foi promovido juntamente com o V Congresso Brasileiro de Saúde Coletiva (ABRASCO) e ocorreu pela primeira vez no interior do estado, em agosto de 1997, na estância hidromineral de Águas de Lindóia, com o tema "Saúde, responsabilidade do Estado contemporâneo".

O VI Congresso Paulista contou com o apoio da Faculdade de Saúde Pública da Universidade de São Paulo, da Secretaria de Estado da Saúde de São Paulo, e do COSEMS - Conselho Estadual de Secretários Municipais de Saúde "Dr. Sebastião de Moraes". Esta sexta versão foi realizada de 17 a 20 de outubro de 1999, novamente na estância hidromineral de Águas de Lindóia, SP. Os pesquisadores, professores, estudantes, gerentes e 
administradores de serviços de saúde pública presentes no $\mathrm{V}$ Congresso aprovaram o interior do Estado como espaço ideal para realização do evento e congrassamento entre os participantes o que justificou novamente a escolha da cidade de Águas de Lindóia.

Para se chegar ao conteúdo e formato finais do Congresso foram feitas consultas a mais de uma centena de instituições de diferentes áreas (instituições de ensino superior, instituições de pesquisa, serviços de saúde, associações de categorias e outras), configurando o aspecto democratizante que pretendeu-se para o Congresso como espaço amplo e significativo de debates e proposição de alternativas de incremento à saúde coletiva.

\section{A TEMÁTICA}

O tema escolhido para essa oportunidade foi Saúde na Cidade. A justificativa para essa escolha deu-se, entre outros, pelo fato de que no início do próximo milênio a quantidade de pessoas morando em cidades será bem maior do que aquela que habita nas áreas rurais. No Brasil, atualmente, mais de $80 \%$ da população já vivem em áreas urbanas ${ }^{1}$. Este fenômeno, que pode ser considerado uma revolução urbana, é característico da segunda metade deste século $^{2}$. Isto transforma a questão da cidade, a questão da urbanização das populações, a questão do modo de vida nas cidades em algo que deve ser enfrentado com atenção e urgência.

As cidades representam, hoje, não apenas o cenário de serviços, tecnologias, produção e possibilidades de vida bastante desenvolvidas, como também representam a acumulação de problemas de natureza tanto estrutural como contingencial. Nestes últimos anos, a cidade absorveu muitas mudanças. Permaneceram entretanto como motor do desenvolvimento econômico, cultural e científico; sendo consideradas, hoje, centros mundiais destes processos.

Desta forma, nas cidades ganham expressão todos os problemas relativos às populações: saúde, educação, ambiente, trabalho, habitação, abastecimento, serviços, lazer, dentre tantos outros. Neste sentido, torna-se fundamental considerar de forma integrada todos os problemas das coletividades no contexto urbano.

\footnotetext{
1 A taxa de urbanização para o Brasil, de acordo com o censo de 1996, é de 78,4\%. Para a região Sudeste - de maiores densidade populacional e nível de industrialização - é de 89,3\% (Fundação IBGE, Contagem da população 1996,1997 v.1), e para o Estado de São Paulo é de $93.11 \%$ (IBGE, home page, Dezembro de 1998; SEADE, home page, Dezembro de 1998).

2 Oliveira e simões (1986) dividem o processo industrialização-urbanização-condições de vida no Brasil em duas etapas: 1) os anos 40-60, início da industrialização e migração rural, com intensificação do controle de doenças, importação de tecnologia médica e expansão da rede hospitalar, significando aceleração da tendência de queda dos índices de mortalidade e aumento na expectativa de vida; e 2) a partir da década de 60 , aceleração do processo de industrialização sob mandato econômico com governo centralizado, intensificação da migração rural-urbana e piora das condições de vida nos centros metropolitanos (apud Szwarcwald et alli, 1992, p.255).
} 
A saúde tem sido um dos aspectos mais emblemáticos dessa realidade. São constantes as referências nos meios de comunicação de massa aos problemas da violência, da poluição do ar e das águas, da qualidade e do acesso aos serviços, da determinação das condições de moradia na condição de saúde da população, dentre outros. O sistema de saúde tem também, cada vez mais, detectado problemas relativos à vida urbana. Dados epidemiológicos e de organização e produção dos serviços têm confirmado esta problemática (LIRA, 1999) ${ }^{3}$.

No Estado de São Paulo, hoje, segundo o IBGE (1996), 93,11\% da população vivem em área urbana. Buscar alternativas e soluções para estes problemas requer esforços e estratégias conjuntas e multi-setoriais, levando em consideração demandas e expectativas dessa população que vive majoritariamente em nossas cidades.

O setor saúde pode e deve contribuir para a formulação dessas novas e urgentes alternativas, articulando-se com os demais setores identificados com as causas de determinação das condições de vida dos que habitam nas cidades.

\section{O CONGRESSO}

O VI Congresso Paulista foi desenhado a fim de privilegiar a manifestação do Congressista através da exposição destacada de seus trabalhos e a oportunidade de discussão, apresentando uma estruturação inovadora, tendo sido iminentemente temático e estruturado em três eixos norteadores das discussões e apresentação dos trabalhos científicos, a saber:

- Condições de Saúde e Qualidade de Vida na Cidade, que contemplou as questões relativas aos determinantes do processo saúde-doença;

- Planejamento e Gestão para a Cidadania, que procurou estimular a abordagem da intersetorialidade;

- A Defesa da Saúde nas Cidades, que promoveu a discussão sobre possíveis parcerias e os direitos dos cidadãos na solução de problemas.

O evento teve sua programação organizada segundo esses eixos temáticos por dia, ao qual correspondiam todas as atividades seqüentes. As Mesas Redondas, que inauguravam a programação do dia, proporcionaram a referência crítica para o desenvolvimento dos trabalhos,

3 LIRA, M.A. Diretoria do PRO-AIM. Comunicação pessoal. São Paulo 1999. 
marcando proposições quanto à temática em questão. As demais atividades aprofundavam ou ampliavam os temas propostos. Desta forma, buscou-se alcançar o nivel de debate e reflexão pretendidos para o evento.

Essa estrutura orientou também a seleção dos Cursos e Oficinas que foram oferecidos como atividades pré-Congresso, assim como orientou as inscrições dos trabalhos científicos, os temas dos Painéis e dos Debates.

A categoria privilegiada para a apresentação de todos os trabalhos científicos foi a de Pôster, na qual os trabalhos foram agrupados para a exposição de acordo com os eixos temáticos do Congresso. O privilegiamento desta categoria para a seleção e exposição de todos os trabalhos científicos se deu com o intuito de ampliar o espaço de participação dos congressistas. Criou-se assim não só uma forma padronizada de entrada dos trabalhos para a seleção científica, como também um espaço único onde os trabalhos puderam ser discutidos e avaliados coletivamente, seja pela Comissão de Premiação (grupo de especialistas das respectivas áreas), seja pelo conjunto de participantes do Congresso.

A modalidade Discussões Temáticas foi criada nesta edição do Congresso Paulista, para dar destaque aos trabalhos mais representativos de cada sub tema, de acordo com a avaliação da Comissão Científica. Nesta modalidade, os trabalhos foram apresentados oralmente permitindo maior aprofundamento das temáticas, configurando um mosaico da visão do congressista acerca do tema. Como conseqüência da qualidade das Discussões Temáticas, elaborou-se uma publicação contendo os papers dos trabalhos apresentados nesta modalidade (CONGRESSO, 2000).

As Discussões Temáticas, que propunham apresentar de forma mais concentrada e aprofundada o panorama do conjunto dos trabalhos científicos inscritos, cumpriram seu papel plenamente, sendo sessões bastante concorridas e debatidas. $O$ formato dessas discussões trouxe uma inovação para os encontros da área.

Dos 12 cursos programados foram realizados seis deles, com carga horária de 12 horas/aula cada um, sendo que os outros seis cursos propostos não atingiram o número mínimo de 15 inscrições. Foram, então, realizados os cursos: Territorialização em saúde: a apropriação da base territorial e o planejamento ascendente; Ecologia e saúde: ampliando a concepção do processo saúde-doença; Promoção de saúde e a construção de municípios saudáveis; Da medicina familiar à saúde da família: possibilidades e limites; Utilização de dados censitários para a identificação de desigualdades sociais no nível local; e Vulnerabilidade e ações preventivas em saúde. 
Também foram realizadas três oficinas: A pesquisa em saúde coletiva no Estado de São Paulo: questões e temas estratégicos para avanço; Assistência humanizada ao prénatal e parto; Fórum permanente de formação e desenvolvimento da força de trabalho para o Sistema Único de Saúde.

Complementarmente à estrutura original do Congresso foram organizadas atividades denominadas de Discussões Programáticas que propunham um enfoque mais específico de algumas questões agudas enfrentadas pela saúde pública no contexto atual e, dentro destes princípios, atingiram plenamente os objetivos, pois permitiram ao congressista focar alguns desses problemas tais como a Leishmaniose Visceral e Meio Urbano, o Controle das Neoplasias no Sistema de Saúde, a Implantação das Organizações Sociais na Saúde, a Atual Política de Medicamentos, a Situação da Dengue e outros.

Em relação às edições anteriores, o VI Congresso Paulista apresentou um crescimento físico substancial de cerca de $30 \%$ do público assistente. Do ponto de vista organizativo foi alcançado um nivel avaliado como ótimo por amostra colhida entre os participantes e que apresentamos na seqüência deste relatório. A avaliação foi, também, bastante positiva a respeito do temário e dos conteúdos apresentados. Abaixo destacam-se alguns aspectos específicos dos resultados científicos do evento.

O número total de adesões ao Congresso foi de 725 congressistas, com fluxo diário de cerca de 900 pessoas. Em relação à profissão dos congressistas houve uma grande diversidade de categorias, com predominância de médicos, enfermeiros, estudantes universitários, cientistas sociais, nutricionistas, psicólogos e professores ${ }^{4}$. Dentre os participantes contamos com representantes de dezesseis estados brasileiros ${ }^{5}$, predominando, evidentemente, os participantes do Estado de São Paulo.

A sessão de Pôsteres contou com intensa visitação dos congressistas e convidados, tendo sido reconhecida como o espaço privilegiado da apresentação dos trabalhos científicos.

4 Número de participantes por categoria profissional, de acordo com a auto identificação dos participantes: estudantes (17), estatísticos (2), engenheiros (7), enfermeiros (58), educadores (2), educador físico (1), economistas (2), diretore de serviços de saúde (1), deputado estadual (1), demógrafo (1), cientistas sociais (15), biomédico (1), biólogos (\$), assistentes sociais (11), arquitetos (6), analistas de projetos (2), advogado (1), administradores (2), veterinários (2), vereador (1), terapeutas ocupacionais (4), tecnólogos (2), supervisor (1), sanitaristas (5), psicólogos (13), promotor de justiça (1), professores (11), pesquisadores (2), odontólogo (1), nutricionistas (13), médicos (67), jornalista (1), historiadores (2), geógrafos (3), fonoaudiólogos (5), físicos (3), filósofo (1), farmacêuticos (8), fisioterapeuta (1), militante de movimentos de saúde (1).

5 Número de participantes por Estado brasileiro, de acordo com as informações fornecidas pelos participantes: São Paulo (435), Rio de Janeiro (48), Minas gerais (11), Distrito Federal (2), Mato Grosso do Sul (10, Mato Grosso (3), Santa Catarina (2), Paraná (14), Bahia (7), Goiás (4), Pará (2), Sergipe (1), Espírito Santo (1), Rio Grande do Sul (3), Pernambuco (5) e Paraíba (1). 
No geral, todas as atividades da programação contaram com um público freqüente $e$ significativo, o que representa que o Congresso conseguiu atingir seus objetivos, expressando de forma equilibrada o 'estado da arte' da Saúde Pública no Estado de São Paulo tendo, desta forma, oferecido ao congressista atividades que contemplavam seus interesses seja em pesquisa ou em serviços.

Com o intuito de também oferecer um registro desse 'estado da arte', os congressistas e convidados receberam, além do livro programa, o livro de resumos (CONGRESSO PAULISTA DE SAÚDE PÚBLICA, 1999) que documenta os 420 trabalhos selecionados pela Comissão Científica para apresentação no evento, reflexo do que se produz na área, hoje. Há muitos trabalhos de universidades (públicas, em sua grande maioria, e, também, particulares), e de profissionais dos serviços, o que revela a extensão e complexidade da área.

\section{O CONGRESSO NA MÍDIA}

A organização do VI Congresso Paulista avaliou que a divulgação tanto do evento como do temário proposto na imprensa leiga era prioritária, configurando uma antecipação de debates e propostas acerca do tema central. Na última edição do Congresso em 1997, havíamos experimentado com êxito a inserção dos assuntos e atividades do evento nesse âmbito. Para esta sexta edição, optamos por um trabalho profissional especializado, com cobertuta regional, priorizando-se os veículos do interior do Estado, sem no entanto deixar de pautar o congresso também na grande mídia. Dessa forma, os esforços de divulgação do evento foram iniciados pela assessoria de impressa do Congresso com cinco meses de antecedência, com a distribuição de briefing sobre o Congresso e o temário a 237 jornalistas de todo o Estado, via correio. Outros 25 jornalistas receberam o material em mãos, durante visitas às redações de veículos da capital. O mailing incluiu revistas mensais, quinzenais e semanais, jornais diários, rádios e TVs. Além da grande imprensa, os veículos especializados em saúde e medicina também receberam o material preparado para a divulgação do evento.

Os veículos especializados em saúde e medicina que receberam o material relativo ao evento foram Jornal do Conselho Médico, Jornal dos Laboratórios, Pharmacia, Secretários de Saúde, Suprimentos e Serviços, Pediatria Moderna, Arquivos Científicos, Comércio Farmacêutico, Revista da Associação Médica, Hospital, Jornal da Sociedade Científica Brasileira, Medicina Nacional, Atualidades em Geriatria, Jornal da Associação Médica Brasileira, Boletim do Colégio Brasileiro de Radiologia, Sindhosp, Jornal do Cremesp, Jornal Santa Casa de Saúde de Ribeirão Preto, Diálogo Federativo, Boletim Informativo Oficial da Sociedade de Medicina e Cirurgia de Campinas. 
$\mathrm{Na}$ tabela, a seguir, apresentamos a forma e o espaço de divulgação que o $\mathrm{VI}$ Congresso Paulista de Saúde Pública teve em cada veículo de comunicação abordado.

VEÍCULO

Folha de São Paulo

Jornal de USP

Jornal da UNICAMP

Home Page UNESP

Home Page USP

Home Page UNICAMP

Jornal do COSEMS

Revista de Saúde Pública e Hospitalar

O Prefeito

CBN

TV Bandeirantes/Programa Dia a Dia

Rádio USP

Jornal da APM

Jornal da CREMESP

Jornal da ABM

Revista da Folha

Jornal de Sorocaba

Jornal de Franca

Jornal de Araçatuba

Jornal de Araraquara

Jornal de Águas de Lindóia

Rádio Cultura AM

Rádio Cultura AM

Globo Campinas

Globo São Paulo

Folha de São Paulo
ESPAÇO

Nota

Pequena matéria

Nota

Nota

Nota

Nota

Matéria

Matéria

Artigo

Entrevista pessoal

Entrevista pessoal

Entrevista pessoal

Coluna Agenda

Coluna Agenda

Coluna Agenda

Envio de repórter ao Congresso foi cancelado na véspera por falta de equipe

Matéria

Matéria

Matéria

Matéria

Matéria

Entrevista pessoal

Presença no Congresso. Duas entradas ao vivo durante o Congresso.

Realização de 10 entrevistas, que foram ao ar durante a programação dos meses de outubro e novembro de 1999

Entrevista pessoal e matéria

Entrevista pessoal e matéria

Apresentou grande interesse em realizar matéria e cobertura. Chegando a pedir contato com vários congressitas. 
No Interior do Estado, editores do Vale Paraibano de São José dos Campos, 0 Imparcial de Presidente Prudente, Correio Popular de Campinas, Diário do Povo de Campinas e Jornal da Cidade de Bauru informaram terem noticiado a realização do evento em forma de agenda.

Alguns outros jornais do interior (Jornal de Piracicaba, Diário de Mogi de Mogi das Cruzes e A Tribuna de Santos) informaram também terem interesse em noticiar o Congresso, embora fosse um evento fora de suas cidades. Caso não houvesse espaço para isso na época do evento, aproveitariam essa pauta para outras ocasiões. Com o jornal Folha Vale, da região de São José dos Campos, foram feitos contatos iniciais para a realização de uma matéria específica, o que acabou não ocorrendo.

Em termos de mídia televisiva, também foram estabelecidos contatos com os editores do programa Fantástico que optou por não cobrir o evento porque considerou a pauta muito local.

\section{AVALIAÇÃO DO CONGRESSO PELOS CONGRESSISTAS}

Com o objetivo de colher a avaliação do Congresso pelos congressistas, foi elaborado um questionário com perguntas de tipo fechada e aberta. Este instrumento foi entregue junto com o restante do material contido nas pastas dos participantes. Solicitou-se a devolução dos questionários ao final do Congresso, não sendo necessário a sua identificação, apenas a categorização quanto ao tipo de instituição de origem: universidade, serviços de saúde e outras.

Os resultados apurados nos questionários foram agrupados em três itens: o local e a época de realização do congresso; a temática e a programação (incluindo as avaliações feitas a respeito da pertinência da temática do Congresso, a sua apresentação sob a forma de eixos e sub eixos temáticos, as modalidades de apresentação dos trabalhos científicos e a programação em geral); e a organização do evento.

Obtivemos um retorno de 79 questionários, representando $11 \%$ dos participantes do Congresso. Não houve grandes diferenças nas respostas em relação às categorias de origem dos congressistas. Portanto, optamos por apresentar de forma agrupada as respostas, de acordo com os itens do questionário (anexo):

1. Sobre o local e a época de realização do VI Congresso Paulista de Saúde Pública: $85,0 \%$ consideraram a cidade de Águas de Lindóia como um bom local para a realização do 
Congresso; quanto ao Hotel Vacance, onde ocorreu o evento, $89,8 \%$ o consideraram bom. Quanto à época de sua realização, $91,2 \%$ dos participantes consideraram a época adequada.

2. Sobre a temática e a programação do Congresso: $13,9 \%$ consideraram a temática regular e $84,8 \%$ a consideraram boa; quanto a estrutura do Congresso, dividida em eixos e sub eixos, $79,7 \%$ consideraram uma boa forma de organização, $14,0 \%$ consideraram regular o modelo adotado e apenas $6,3 \%$ avaliaram negativamente (conceito ruim) tal forma de organização; sobre as modalidades de apresentação dos trabalhos cientificos, a maior parte dos congressistas $(78,5 \%)$ considerou-as adequadas.

3. Sobre a organização do evento, observou-se segundo comentários dos congressistas, que:

- houve satisfação com a programação em seu conjunto porque permitiu ao congressista conhecer e tomar contato com a produção da área. Referiu-se que o Congresso reconheceu todo o campo da Saúde Pública;

- os congressistas reconheceram e aprovaram a proposta deste Congresso de valorizar o Pôster como categoria principal para a apresentação dos trabalhos cientificos. Por outro lado, foram feitas críticas quanto à forma de montagem dos pôsteres e quanto à inadequação do local destinado para a exposição dos mesmos (local sujeito a muito calor e vento que dificultaram a montagem dos pôsteres e sua visitação);

- as Discussões Temáticas também foram reconhecidas como espaço de valorização de apresentação dos trabalhos e aprofundamento de questões. Os aspectos negativos referiram-se a falta de tempo para discussão nas sessões, ausência de alguns apresentadores em algumas sessões e composições de sessões com trabalhos muito distintos entre si;

- os congressistas reclamaram da coincidência, em termos de horário, de algumas atividades com temas próximos, o que dificultou o acompanhamento de todas as atividades de interesse;

- houve o reconhecimento da instância congresso como espaço de atualização e intercâmbio dos profissionais das universidades e dos serviços que trabalham na área. Recomendou-se uma contínua estimulação desse intercâmbio;

- a Comissão Cientifica foi elogiada pela seleção dos trabalho e criticada pelas indicações que separaram os trabalhos nas modalidades Pôster ou Discussão Temática. Outra crítica referiu-se a não disponibilização para reprodução no local dos textos apresentados pelos palestrantes e congressistas; 
- a Comissão Organizadora recebeu críticas relacionadas com o não cumprimento rigoroso dos horários estabelecidos pela programação e também pelos pequenos intervalos previstos entre as atividades (término de uma atividade e início da atividade seguinte). Além disso, apontou-se como aspecto negativo a falta de alternativas culturais de lazer e esportivas.

Em termos mais gerais, sobre a organização do Congresso no contexto da agenda da Saúde Pública, foi sugerido a regularidade de realização de dois ou três anos e a sua localização no interior do estado, a fim de permitir maior participação dos profissionais dessa região. Apontou-se, também, que o Congresso Paulista de Saúde Pública deve ser organizado a partir de atividades preparatórias (pré-congresso) em diferentes locais do estado, com a participação de diferentes faculdades e universidades, a fim de facilitar a participação tanto de estudantes, como de profissionais vinculados aos serviços de saúde. Essas atividades précongresso culminariam com a realização do Congresso, como uma atividade convergente $e$ de espaço para aprofundamento das discussões iniciadas localmente.

\section{CONSIDERAÇÕES FINAIS}

O VI Congresso Paulista de Saúde Pública representou a retomada dos esforços que, desde 1977, vinham sendo dirigidos à realização de um evento de discussão acadêmica no âmbito do estado de São Paulo. Especialmente nesta sexta edição, procurou-se dar contornos nitidamente regionais (e não regionalistas) ao Congresso Paulista de Saúde Pública, priorizando instituições paulistas tanto na aferição de interesses a serem abordados, como na definição do temário e dos convidados a desempenhar o papel de estimuladores do debate desejado, a partir das atividades programadas. Embora o temário tenha sido de interesse supra-regional, essa explícita intenção decorre do fato de que o calendário nacional de eventos na área da saúde pública e coletiva já contempla as possibilidades de discussão acadêmica e de proposição política para a área, especialmente o Congresso Brasileiro de Saúde Coletiva e o Congresso Brasileiro de Epidemiologia. Nesse sentido avaliou-se que, em âmbito regional poderíamos estabelecer através do Congresso Paulista, uma agenda que ao mesmo tempo examinasse a produção da área, originada tanto no meio acadêmico, como também aquela advinda do relato de experiências e observações sistematizadas nos serviços de saúde, compondo uma agenda sem conflitos e de ampliação das possibilidades existentes.

No entanto, o fato de termos realizado um evento com essas características mostrou que as dificuldades de organização não foram menores do que nas edições conjuntas com a Sociedade Brasileira de Higiene, em 1977, e com a Associação Brasileira de Pós-Graduação em Saúde Coletiva - ABRASCO, em 1983, 1989 e 1997. Ao contrário, por se tratar de evento 
regional de médio porte, encontramos uma imensa e inesperada dificuldade em captar recursos de agências oficiais tradicionais financiadoras de eventos técnicos e científicos na área. Afirmamos que não é exagero considerarmos haver um certo preconceito desses financiadores, seja com a dimensão do evento, seja com a abrangência e diversidade do temário para além da focalização exigida pelas atuais políticas de financiamento mais voltada para as ciências básicas, secundando as áreas aplicadas. A comprovar nossa afirmação, nos valemos dos pareceres iniciais dessas agências, denegando nossos pedidos, e dos percalços sofridos pela organização quanto ao recursos governamentais orçamentariamente destinados a essas atividades.

Contudo, avaliamos que o Congresso Paulista de Saúde Pública deva ser aprimorado como um espaço plural com ampla participação do Congressista, através das manifestações contidas em estudos, projetos, programas e relatos oriundos dos serviços de saúde, sem detrimento do produto de origem e natureza acadêmicas. Também há a necessidade que esse evento amplie e sistematize sua manifestação de cunho político, avaliando, opinando e recomendando caminhos para as políticas públicas de saúde no âmbito regional e mesmo nacional por corolário. Com isto, pretende-se adensar o substrato para uma agenda política mais articulada e coesa no interregno dos Congressos Paulistas, cumprindo-se com um mandato explícito da APSP, que é o de influenciar sociedade e governo no desenvolvimento das politicas públicas no âmbito de interesse da saúde pública e coletiva.

\section{REFERÊNCIAS BIBLIOGRÁFICAS}

CONGRESSO PAULISTA DE SAÚDE PÚBLICA: Saúde na cidade, como garantir a qualidade de vida na cidade?, $6^{\circ}$, Águas de Lindóia, 1999. Anais. São Paulo, APSP, 2000.

CONGRESSO PAULISTA DE SAÚDE PÚBLICA: Saúde na cidade, como garantir a qualidade de vida na cidade?, $6^{\circ}$, Águas de Lindóia, 1999. Livro de resumos. São Paulo, APSP, 1999.

CONGRESSO PAULISTA DE SAÚDE PÚBLICA: Saúde na cidade, como garantir a qualidade de vida na cidade?, $6^{\circ}$, Águas de Lindóia, 1999. Livro programa. São Paulo, APSP, 1999.

FUNDAÇÃO IBGE. Censo populacional 96. [online] Disponível em URL: http://uww.ibge.gov.br/ [15 ago. 1998] 
FUNDAÇÃO SEADE. [online] Disponivel em URL: http://www.seade.gov.br/ [ago/dez,1998, jan.1999]

SZWARCWALD, C. L. et al. Mortalidade infantil: o custo social do desenvolvimento brasileiro. In: LEAL, M.C. et al. Saúde, ambiente e desenvolvimento. São Paulo: HUCITEC/Rio de Janeiro: ABRASCO, 1992, v.2, p.251-78.

\section{A GLANCE ON THE $6^{\text {th }}$ CONGRESS FROM SÃO PAULO OF PUBLIC HEALTH}

SUMMARY: The authors make an evaluation of the VI Congresso Paulista de Saúde Pública, based both on preparation documents for the meeting, and on an evaluation of the Congress activities, made by its participants. They comment on organizational aspects, as well as on the origin and occupation of the participants.

KEY WORD: public health, scientific event, evaluation and health in the city 


\section{ANEXO \\ AVALIAÇÃO DO VI CONGRESSO PAULISTA DE SAÚDE PÚBLICA ÁGUAS DE LINDÓIA}

17 a 20 de outubro de 1999

Prezado Congressista,

Gostariamos de contar com a sua colaboração no preenchimento desta Ficha de Avaliação do VI Congresso Paulista de Saúde Pública.

1) O que você achou do local escolhido para a realização deste evemto?

- Cidade de Águas de Lindóia Bom Regular Ruim

- Hotel Vacance _Bom _ Regular _ Ruim

2) A época de realização do Congresso foi adequada? Sim _ Não

3) Você considera que a temática do Congresso foi: _ Boa _ Regular _ Ruim

4) A programação do Congresso esteve adequada à temática geral? $\operatorname{Sim}$ Não

5) De quais atividades você mais gostou? 1)

2)

3)

6) De quais atividades você não gostou?

1)

2)

3) 
7) Como você avalia a estrutura adotada de trabalhar com Eixos e Subeixos temáticos? Bom Regular Ruim

8) Você considera que a forma de apresntação dos Trabalhos Científicos dos Congressistas foi: Adequada Inadequada

Por que?

9) Outros comentários e/ou sugestões:

CARACTERIZAÇÃO DO CONGRESSISTA QUE RESPONDEU ESTE FORMULÁRIO:

TIPO DE INSTITUIÇÃO A QUE PERTENCE:

- Universidade

- Docente

- $\quad$ Aluno de Pós-Graduação

- Aluno de Graduação

- Serviços de Saúde

- Instituto de Pesquisa Científica 